\title{
CONCOMITANCE OF HIGH-LEVEL SPORT
}

\author{
Motto: Concomitance is a product of conceptualised sport
}

\author{
Adrian DRAGNEA ${ }^{1 *}$ \\ ${ }^{1}$ National University of Physical Education and Sport, Faculty of Physical Education and Sport, Bucharest, \\ Romania \\ *Corresponding author: adriandragnea2105@gmail.com
}

https://doi.org/10.35189/dpeskj.2021.60.2.1

\begin{abstract}
The athletic gesture is primarily a spectacular product that induces aesthetic feelings to those who perform it and the spectators as well. Interconnection and interaction through communication are concomitantly achieved, generating an eminently psychosocial process as the prerogative of both those with reputation and the initiated audience. Concomitance appears as nonverbal motor ease resulting from professional and social skills, sport being a fertile ground for its manifestation. It is desired and appreciated by both athletes in the arena and the public that participates in formative or competitive events, regardless of the branch of sport. The factors with an impact on the range of concomitance are cognitive, affective and social in nature, representing indicative landmarks for managers in forming and leading sports teams. Performance is the criterion for team assessment. A particular form of concomitance arises between the partners playing in doubles teams or those constraint by regulations to play in other teams of up to eight people. The affinity between members is highlighted by the reflexively applied and perfectly coordinated choreography. Any high-value performance is achieved through concomitance, which involves suffering and pain that are endured with stoicism and joy (As a form of masochism?). It is the art of suffering, which reveals what is beautiful and good. The sublimity of the performance is concomitantly experienced with great intensity by both athletes and spectators.
\end{abstract}

Keywords: concomitance, suffering, pain, top-level athletes, spectators.

\section{Introduction}

High-level sport is par excellence spectacular, a generator of values, an original performing art and the product of a creation in time and space, which is charged with multiple meanings that those in the arena are ready to make known by revealing themselves to the public during a valorising ceremonial, the competition. The athletic gesture is a priority, an artistic product that induces intense feelings concomitantly with its performance (to note that concomitance occurs at the same time, is technically synchronised, cognitively and emotionally charged, involving coordination between two or more people). Its theme and the way of performing it are in the spirit of the times (Zeitgeist), which confers it authenticity and originality. Interconnection and interaction through communication and movement produce concomitance, a phenomenon of real harmony, as a symphony of acts and actions of different types. Its psychosocial essence is driven by the social brain, which makes people sociable. The emotions arising from the most common encounters deeply affect the whole body: cascades of hormones with a role in regulating systems are sent from the heart to the white blood cells (Goleman, 2018).

Concomitance appears as nonverbal motor ease resulting from professional and social skills, sport being a fertile ground for its manifestation. It is desired and appreciated by both athletes in the arena and the public that participates in formative or competitive events, regardless of 
the branch of sport. Pleasure and satisfaction are experienced with great intensity by athletes and spectators.

\section{Factors with an impact on concomitance in sports groups}

An overview of the range of concomitance triggers functional delimitations between the types of intellectual, emotional and social knowledge. Perceptions, representations, impressions, mental imagery, verbal, kinaesthetic, tactile and chromatic communication, social experience, all these determine concomitant actions and activities. Affectivity and emotional intelligence play an essential role, while empathy, emotional resonance, self-image, feelings, affinities and passions are processes that operate within the system.

\section{Impression, knowledge, intragroup human condition}

In the universe of concomitance, performers learn how to appreciate the values of physical and social efforts that help them develop, surpass themselves on a curve resulting from the vertical and the horizontal, but also discover the systole and diastole of tension and relaxation connected to the rhythms of natural and social environments.

A performer is defined by the set of tendencies that push them to go beyond the human condition. In this process, any action becomes a method, provided that this term is understood as the very opposite of the pragmatic, motor or intellectual habit (routine), the automatisms of life, training and competitions.

The method as a spiritual and moral renewal... as the beginning of the road and a provisional guide to a human adventure of self-transcendence (Bachelard, 1986).

In order to reach the concomitance accepted as an "ideal" level, athletes will exploit the indefinite potential of their energies, will awaken and personalise themselves in harmony with another/others. "He who no longer ascends, descends, he who does not raise, decays" says the aforementioned French philosopher. This means to live with intensity the vocation and joy of an increasing and verticalizing "beginning" against what is habitual and a habit. To get started, unlearning (breaking off an old, frozen habit) should be learned by inhibiting the first comfortable reactions; this is followed by an awakening and the grafting of new elements and procedures, behaviours and forms of reconstruction. Getting out of a motor, verbal, cognitive or emotional habit, leaving off the intuitions of the common sporting life or depsychologization also involves verification-related re-psychologizations that lead to new realities; these refer to the (automated) disturbance and mystification of abstractions about the world, relationships and events, regardless of the individual's willpower.

In a philosophical context, concomitance has well-ordered properties built over time, which ensure its harmonious, aerial, fragile and free-like-a-sonnet coherence. 


\section{Topic Addressed}

Thinking drives the athletic being. The coaches' advice becomes a time of creation, renewal and reconciliation in the struggle for performance.

Between athletes and coaches, there is an emotional relationship in which movements, demonstrations and their replication by the athlete make participants friendlier, happier, more enthusiastic and more willing to transmit and learn. The high level of coordination indicates that those involved like each other and have a high level of trust. Briefly, the coordination of moods is the essence of interpersonal relationships (Goleman, 2008).

Concomitance arises from an athlete's imaginary, and in turn the athlete themselves is an $\mathrm{x}$ ray of the impressions that will become, someday in the future, intentional coordination, an idea expressed as a representation (from top to bottom). This approach gives rise, along with the method, to the obsessions for one sport or another. The concomitance of behaviour is an objectification of the subjectivity of impressions, imaginary and ideas. Thus, systematised mental mapping collections are obtained, which spring from concomitant athletic practices.

Managers' actions in the process of team formation and reconfiguration involve recruiting and including athletes from other groups in the structure of the teams they train. Ensuring that concomitance works properly is the spectacular goal of actions. The impressions (also called stereotypes or generalisations: "Tell me what team you come from to tell you who you are") on which managers are based involve knowing the features of the groups from which the targeted athletes come and the influence of those groups on them. This is the "first impression" that matters and which will be complemented and reformed over time. The following steps are distinguished:

1. Features of the group to which the athlete belonged; current traditional and competitive sports values, level of competitions, results, team management, specialists (recent history);

2. Opinions of other specialists and the media regarding the value of the group based on criteria other than the official ones, stars recognised as such, comments on the results. Competitor's reputation. (Moscovici, 1998)

3. Generalisation (conclusions), which can be positive, negative or neutral.

A profile of the group influences that can be found in the athlete to be transferred is thus achieved; impressions based on opinions such as "the athlete is red-haired, is sympathetic or unlikable; I have heard that..." should be avoided because these characterisations are usually unfavourable and confusing.

Top-level athletes have a superior ability to adapt and act concomitantly due to their competitive and life experience, which is why their transition from one team to another (such as the summoning to the national team or the transfer to another team for a specified period) is achieved without difficulty. Social cognition, knowledge of how the team works, expectations in group social situations, training sessions, ability to decipher nonverbal cues, game management, trends in the game concept, teammates' interindividual preferences and many more facilitate integration into (assimilation of) the concept of preparation and approach to competitions but also into the game system, and thus compliance with the activity protocol occurs very quickly, within 1 to 4 days, without any decrease in efficiency. Motivation plays 
an important role. The players' readiness to learn and relearn enables them to integrate very fast into the team structure.

An original phenomenon that fosters concomitance is groupthink (Janis, 1972) that occurs in athletes who are part of a cohesive team, where the desire for unanimity is stronger than the desire to explore other alternative ways of action. Maintaining group cohesion is the unshakable goal. Concomitance reflects groupthink, but there are also some disadvantages such as the danger of replacing independent critical thinking, which is essential in solving problematic situations in sports games and not only. Groupthink is a framework of principles and norms for the manifestation of creative situational thinking in solving game phases.

This form of thinking is crucial in the activity of the staff/team in all phases of the training and competition, ensuring the unity of analysis and decision.

We imitate the happiness of winning players, successful scorers or passers with a big smile on our faces, with a burst of applause sometimes accompanied by short verbal phrases or whistles. These are emotional reflections. The show is prepared before experiencing emotion, satisfaction, or minimising failure by displaying less disappointment.

When the phases in the arena consist of deceptive movements (feints), actually elements performed with precision, the brain region that governs the movement gets into action, and in dramatic situations (accidents) involving unexpected changes, the emotional centres come into play. Everything that happens on the field at any moment also happens in the brains of spectators in the stands: "A thing is real if it has real consequences".

\section{Concomitance in the teams made up of two athletes (pairs, doubles, tandem)}

Concomitance is the result of an emotional exchange, a transfer that sometimes occurs imperceptibly during encounters. Emotions are contagious. Emotional intelligence makes the exchange of sympathy either charming or repulsive (see combat sports) in social relationships. Sport lovers (spectators) show on their faces the affinities to the athletes in the arena through posture and gestures in a perfectly coordinated, well-defined and learned choreography.

In sports or events for two athletes: doubles - tennis, dance couples/pairs - figure skating, doubles - rowing, aerobic sport, etc., concomitance is the result of motor synchronisation and emotional interaction. In psychological terms, it is considered that the more skilful one of the two athletes is, the better that person controls the transmitted signals. Yes and no, because the role in action coordination can be alternately played depending on the situations that arise during training and competition. The "power" of one of the counterparts resides in determining the other's emotional state - Zeitgeber (a name taken from biology, which involves biological rhythms); for a couple of dancers, music becomes the Zeitgeber of the body, with the dominant partner talking more and the submissive partner looking more at the other's body, and this is the environment through which emotion is conveyed (Goleman, 2008).

In figure skating (ice dance couples or pairs), motor synchronisation is achieved through nonverbal cues, mutual reactions occur instantly "without thinking too much", movements and transitions-connections occur smoothly, harmoniously and expressively. A simple artistic gesture, a touch, a tilt of the head, a blink, a look, all of these are learned signals that trigger an action or mark a moment in the programme (neuroscience calls this phenomenon the "lower 
path" of the brain, which escapes conscious introspection). Desynchronisation of one of the two athletes in a phase of the exercise disturbs that partner, who gets into a pre-anxious state, a situation that requires a significant effort of will and concentration to "move on". The physical and emotional support provided by the partner alleviates sadness and favours the continuation of the exercise. Concomitance envelops them like a mental and affective aura in a world of their own, where music and ice are the natural artistic and sporting background. The power of transmitting feelings, emotions and repeated feedback appears as an emotional contamination or emotional resonance. (Goleman, 2018) This process is the genesis of performance. The mutual contamination of the two goes further, also affecting the group of companions, fans and spectators, who respond with applause and cheers as recognition of their performance. It is the concomitance sought by any ice skater.

The formation of ice dance couples takes into account the affinity revealed by body posture and movements reciprocally mirrored in the reflexively applied and perfectly coordinated choreography. Physiological harmonisation is fundamental. Carl Marli (2004, cited by Goleman, 2008) analysed the level of perspiration in two soloists and emphasised brain activity as an interpersonal dance taking place in an "empathetic logarithm". Affinity exists only between people (is that so??), and in top athletes, it is exemplary and occurs voluntarily, pleasantly, naturally, with positive feelings (in combat sports, there is close physical coordination between two athletes-opponents but there are no positive feelings and affection) and a highly-coordinated nonverbal duet.

The more two skaters perform various combined and increasingly complicated technical procedures at the same pace, the more intense their positive feelings. The concomitance between them is reflected in their respiratory systems and heart rates. Synchronisation produces deep pleasure. Performing a dance to a piece of music is similar to two violinists who perform a double Bach concerto, the rhythms of neural activities of their right hemispheres being very close. The synchronisation of these areas is much higher between the brains of the two athletes than between the left and right hemispheres of the same brain. The sublimity of ice dancing is born by sliding, a phenomenon that trivialises the safety of the support.

\section{The concomitance of suffering and pain}

People usually talk with admiration about performers, highlighting their aesthetics, technical styles, efficiency, spectacular phases and, of course, performance, which is actually the core of appraisals. The athlete is a symbol of performance. We have in mind the images of rowing and kayaking teams made up of 2 to 8 athletes moving to the cadence of a pendulum clock, the synchronisation of their strokes producing aesthetic emotions and confusingly disturbing affectivity. Evoking precise and complex kinaesthetic skills focuses the analysis of the efforts made by athletes. But the phenomenon is more complex, the technical excitement radiates, becomes mental vision, invades the whole sensory area, and the entire soul literally resonates. The kinaesthetic (technical) impression disturbs everything and produces various mental images developed according to a programme known only to the athlete. The stroke cadence is the very background on which sounds with original musicality take place. Where 
are the sensations produced by the supramaximal effort? However, concomitance is born from this functional aspect, and performance is its fruit.

The complex of organic demands, mental demands and encouragements brings suffering to athletes, but they only show it to the viewers through their mimic, grimaces and expressions in their eyes. It is the art of suffering: athletes show others something beautiful and good without settling in the position of those who consider themselves unique; however, they master the truth, knowing the fragility of performance, the turmoil of questions and even their own weaknesses.

Sport is mind and heart, the intelligence of the heart, an integrative virtue. Those who suffer for the desired ideal, namely performance, experience pain with stoicism, and people around them only see the tears in their eyes and their smiling faces. This is the price of concomitance. The experience of suffering and its de-structuring threat turn into moaning and shout. In the book A Grief Observed, Lewis (1961) makes an x-ray of suffering by investigating the problem of grief. The author states that the experience of pain and suffering can become a place for the unpredictable and informal encounter with the divinity and oneself. How is it possible not to give in to self-pity and not to drown looking at the picture of your own grief?

The athlete can de-structure the self-rescue and comfort systems in which we encapsulate them almost involuntarily. The audience becomes part of this show performed by athletes as a grieving person who goes through a personal restorative, healing experience. How unfair it is to blame them in case of failure! The concomitant presence of the public replaces the loneliness of suffering. The consolation and grief experienced by the spectators who support their hero is helpful, strengthening and a generator of joy by removing pain.

Talking about a performer's skills, a famous rowing coach mentions that the fundamental feature of performance is pain tolerance in shocking workouts and exhausting competitions.

The two forms of training and self-expression have physical, neuropsychological and social entropic effects, meaning total imbalance. It is a decline of the human being as a result of a personal choice rather than for moral reasons. This is a dramatic reality, and the world is dancing or moaning. But life requires recovery or return in order to become the athletic being before the challenge, and even more. The athlete's rebirth is the rebirth of the world that is admitted (Scrima, 1947, cited by Manolescu, 2020), which is singing and dancing. The restored being is a new form of release able to re-enter the competitive space.

The athlete and the audience experience together the sublimity of performance as an impetuousness of strength, admiration of tenacity, perfection of gesture and musicality of the ambience. After each cycle of exhaustion, the athlete redesigns their personal destiny through physical, mental and social reconstruction.

\section{Conclusion}

Concomitance is a psychosocial phenomenon that involves the interaction between athletescoaches and the audience.

The area of concomitance includes the types of intellectual, emotional and social knowledge through forms of verbal and nonverbal communication. 
Athletes define themselves and attempt to overcome their human condition in the spectacular universe of concomitance.

An emotional connection is established between athletes and coaches, the moods being the essence of interpersonal relationships.

Ensuring intragroup and intergroup concomitance is a spectacular goal of high-level sport.

Performance groups that arouse the concomitant feelings of the audience are based on the reputation of the athletes included in these groups.

Concomitance is highlighted in two ways, namely between the counterparts of an athletic couple and between them and spectators.

In a couple of athletes or any other formation, the more complex the technical procedures, the more intense the positive feelings.

The concomitance of suffering and pain induced by aesthetic emotions increases the spectacularity and emotional feelings of the public.

The athlete and the audience experience together the sublimity of performance as an impetuousness of strength, admiration of tenacity, perfection of gesture and musicality of the ambience in concomitant pleasure.

\section{References}

Bachelard, G. (1986). Dialectica spiritului științific modern (Vol. I) [Dialectics of the modern scientific spirit]. Editura Ştiințifică și Enciclopedică.

Dragnea, A. (2006). Elemente de psihosociologie a grupurilor sportive [Elements of psychosociology of sports groups]. CD Press.

Dragnea, A., Bota, A., Stănescu, M., Teodorescu, S., Șerbănoiu, S., \& Tudor, V. (2002). Teoria educației fizice și sportului [Theory of physical education and sport]. FEST.

Goleman, D. (2014). Focus. Motivația ascunsă a performanței [Focus. The hidden motivation for performance]. Curtea Veche.

Goleman, D. (2008). Inteligența emoțională [Emotional intelligence]. Curtea Veche.

Goleman, D. (2018). Inteligența socială. Noua știință a relațiilor umane [Social intelligence. The new science of human relationships]. Curtea Veche.

Janis, I. (1972). Victims of groupthink: A psychological study of foreign-policy decisions and fiascoes. Houghton Mifflin.

Lewis, C. S. (1961). A grief observed. Harper \& Row.

Manolescu, A. (2020). André Scrima - Conferințe [André Scrima - Conferences]. Dilema Veche, 872-879.

Moscovici, S. (Coord.). (1998). Psihologia socială a relaţiilor cu celălalt [The social psychology of relationships with the other]. Polirom. 